\title{
Persepsi mahasiswa terhadap lingkungan pembelajaran di Universitas Sam Ratulangi Manado
}

\author{
Linda M. Tompodung \\ Bagian Mikrobiologi Fakultas Kedokteran Universitas Sam Ratulangi Manado \\ Email: linda_tompodung@rocketmail.com
}

\begin{abstract}
Learning environment in any medical school is an important factor to determine quality and curriculum succeses. Students' experience about their learning environment in medical education is related to their achievements, satisfaction, and success. It is important to get reguler feedback from the students on how they experience their learning environment as basis of strategic planning for futher improvement. This study was aimed to assess the educational environment of Sam Ratulangi University (Unsrat) undergraduate medical program from the students' perspective and also to identify the difference in perception between genders. This was an analytical study with a cross-sectional design conducted in October 2016 among undergraduate students of academic year 2016/2017. Data about the learning environment were obtained by using questionnaire of Dundee Ready Educational Environment Measure (DREEM) and further analyzed with the Mann-Whitney test to identify the significance between genders. The total DREEM score indicated more positive than negative perception with rooms of improvement (127/200). The score for all the five subscales of DREEM indicated a more positive perception. The overall mean DREEM score of the females $(128,16)$ was higher compared to males $(126,13)$ but not statistically significant. Conclusion: The medical students of Sam Ratulangi University showed a positive perception about their undergraduate educational environment. Continuous quality improvement and innovation are essentially needed.
\end{abstract}

Keywords: educational environment, medical education, DREEM

\begin{abstract}
Abstrak: Lingkungan pembelajaran merupakan salah satu faktor penting dalam menentukan kualitas dan keberhasilan kurikulum pendidikan kedokteran. Persepsi mahasiswa terhadap lingkungan pembelajaran terbukti memengaruhi prestasi, kepuasan dan kesuksesan mahasiswa. Penting untuk mendapatkan umpan balik berkala dari mahasiswa tentang yang mereka rasakan terkait lingkungan pembelajaran sebagai dasar strategi perencanaan untuk peningkatan di masa depan. Penelitian ini bertujuan untuk menilai lingkungan pembelajaran melalui persepsi mahasiswa dan mengidentifikasi perbedaan jenis kelamin di Fakultas kedokteran Universitas Sam Ratulangi Manado. Jenis penelitian ialah analitik dengan desain potong lintang, dilakukan pada Oktober 2016 terhadap mahasiswa TA 2016/2017. Data persepsi terhadap lingkungan pembelajaran didapat dari kuesioner Dundee Ready Educational Environment Measure (DREEM). Analisis data dilakukan menggunakan uji Mann-Whitney untuk mengidentifikasi perbedaan antara jenis kelamin. Hasil nilai total DREEM menunjukkan lingkungan yang lebih positif daripada negatif dengan ruang untuk perbaikan (127/200). Nilai skor dari kelima sub-skala DREEM mengindikasikan persepsi yang lebih positif. Nilai total rerata DREEM mahasiswa perempuan $(128,16)$ lebih tinggi dibandingkan dengan laki-laki $(126,13)$ namun tidak terdapat perbedaan bermakna antara persepsi terhadap lingkungan pembelajaran berdasarkan jenis kelamin. Simpulan: Mahasiswa kedokteran Unsrat memiliki persepsi positif terhadap lingkungan pembelajaran. Peningkatan kualitas secara berkala dan inovasi merupakan hal yang esensial dalam pendidikaan kedokteran.
\end{abstract}

Kata kunci: lingkungan pembelajaran, pendidikan kedokteran, DREEM 
Fakultas Kedokteran Unsrat menerapkan Kurikulum Berbasis Kompetensi (KBK) sejak tahun ajaran 2007/2008 dan dievaluasi berkala menjadi kurikulum 2012 dan 2016 dengan berpatokan pada Standar Kompetensi Dokter dan Standar Pendidikan Profesi Dokter yang dikeluarkan oleh Konsil Kedokteran Indonesia (KKI). Kurikukum merupakan suatu hal yang holistik, inklusif, dan komprehensif dalam suatu pendidikan. ${ }^{1}$ Karena memiliki aspek holistik dan komprehensif maka kurikulum dapat didefinisikan sebagai segala sesuatu yang terjadi dalam kelas, departemen, fakultas, pendidikan kedokteran, atau seluruh universitas sebagai suatu keseluruhan. ${ }^{1}$

Penilaian lingkungan pembelajaran merupakan implementasi dari pelaksanaan sebuah kurikulum. ${ }^{2}$ Lingkungan pembelajaran sendiri merupakan manifestasi nyata dari kurikulum dan konseptualisasi dari lingkungan, pendidikan dan organisasi, yang mencakup segala sesuatu yang terjadi dalam pendidikan kedokteran. ${ }^{2}$ Federasi Dunia untuk Pendidikan Kedokteran atau World Federation for Medical Education (WFME) menganggap lingkungan pembelajaran sebagai salah satu area yang harus ditargetkan ketika mengevaluasi program pendidikan kedokteran. ${ }^{3}$ Selain itu lingkungan pembelajaran perlu dievaluasi karena terbukti memengaruhi keberhasilan akademik mahasiswa, perkembangan perilaku pembelajar, dan pencapaian tujuan suatu institusi. ${ }^{4,5}$

Persepsi mahasiswa terhadap lingkungan pembelajaran dapat diukur salah satunya dengan instrumen Dundee Ready Education Environment Measure (DREEM) yaitu suatu instrumen pengukuran yang valid dan reliabel yang dirancang untuk mengukur lingkungan pembelajaran pendidikan dokter dan profesi kesehatan lain. ${ }^{6}$ Selain dapat mengukur lingkungan pembelajaran, instrumen DREEM dapat mengidentifikasi kelemahan lingkungan pembelajaran suatu institusi sehingga dapat dilakukan perubahan dalam kurikulum dan meningkatkan kualitas pembelajaran. ${ }^{6}$
Penelitian ini bertujuan untuk menilai persepsi mahasiswa Fakultas Kedokteran Unsrat terhadap lingkungan pembelajaran pada tahun akademik 2016/2017.

\section{METODE PENELITIAN}

Jenis penelitian ini ialah analitik dengan desain potong lintang terhadap mahasiswa program studi kedokteran umum FK UNSRAT. Mahasiswa diminta mencantumkan usia, semester, dan jenis kelamin. Penelitian ini dilaksanakan pada bulan Oktober 2016 di Fakultas Kedokteran (FK) Unsrat, Manado, Sulawesi Utara. Populasi target ialah mahasiswa kedokteran tahap akademik FK Unsrat angkatan 2013 hingga angkatan 2015, yang bersedia dan melengkapi kuesioner DREEM. Pengambilan sampel dilakukan secara total sampling.

Instrumen DREEM terdiri dari 50 butir pertanyaan dan dikelompokkan menjadi 5 sub-skala penilaian yaitu: ${ }^{7} 12$ item persepsi mahasiswa terhadap proses pembelajaran dengan skor maksimum 48, 11 item persepsi mahasiswa terhadap pengajar dengan skor maksimum 44, 8 item persepsi mahasiswa terhadap prestasi akademik dengan skor maksimum 32, 12 item persepsi mahasiswa terhadap suasana pembelajaran dengan skor maksimum 48, dan 7 item persepsi mahasiswa terhadap kehidupan sosial dengan skor maksimum 28. Penilaian dilakukan mengguna-kan skala Likert dari skor 0 untuk sangat tidak setuju sampai dengan skor 4 untuk sangat setuju. Untuk pertanyaan yang bersifat negatif yaitu pertanyaan nomor $4,8,9,17$, $25,35,39,48,50$, pemberian skoring yang diberikan akan terbalik. Hasil penilaian total skor DREEM dikategorikan sebagai berikut: $^{7}$ 0-50 (sangat tidak memuaskan), 51-100 (terdapat masalah), 101-150 (lebih banyak hal positif daripada negatif), dan 151-200 (sangat memuaskan).

\section{HASIL PENELITIAN}

Penelitian ini berhasil mengumpulkan total 311 dari 435 mahasiswa $(71,5 \%)$, dengan distribusi semester 3 (tahun 2015) $68 \%$ dari total 110 mahasiswa, semester 5 
(tahun 2014) 56\% dari total 77 mahasiswa, dan semester 7 (tahun 2013) 77\% dari total 248 mahasiswa. Rentang usia subyek yang termuda ialah 17 dan tertua 22 tahun. Sebagian besar subyek berjenis kelamin perempuan (65\%) (Tabel 1).

Total rerata DREEM menunjukkan bahwa persepsi mahasiswa terhadap kondisi keseluruhan fakultas mencapai skor 127,45 . Hal ini berarti persepsi mahasiswa terhadap lingkungan pembelajaran di UNSRAT bersifat lebih banyak positif daripada negatif serta masih perlu perbaikan (Tabel 2).

Sebaran data persepsi berdasarkan jenis kelamin dengan analisis Kolmogorof-
Smirnov tidak normal, sehingga disajikan dalam bentuk nilai median (maksimunminimum). Persepsi mahasiswa terhadap lingkungan pembelajaran dan subskalanya berdasarkan jenis kelamin, "lebih banyak positif dibanding dengan negatif". Untuk menilai perbedaan signifikan persepsi mahasiswa terhadap lingkungan pembelajaran antara mahasiswa laki-laki dan perempuan, maka dilakukan uji MannWhitney. Berdasarkan uji Mann Whitney, tidak terdapat perbedaan bermakna antara persepsi mahasiswa laki-laki dan perempuan terhadap lingkungan pembelajaran dan subskalanya $(P>0,05)$ (Tabel 3).

Tabel 1. Karakteristik dasar subyek

\begin{tabular}{lcccc}
\hline Karakteristik subyek & & $\mathbf{n}=\mathbf{3 1 1}$ & \% & Rerata \pm SB \\
\hline Jenis kelamin & Laki-laki & 109 & $35,0 \%$ & \\
& Perempuan & 202 & $65,0 \%$ & \\
Semester & & & & \\
& 3 & 75 & $24,1 \%$ & \\
& 5 & 31 & $62,1 \%$ & \\
Usia (tahun) & 7 & & & $20 \pm 1$ \\
\hline
\end{tabular}

Tabel 2. Persepsi mahasiswa terhadap lingkungan pembelajaran di FK Unsrat

\begin{tabular}{lrc}
\hline & Rerata \pm SB & Intepretasi \\
\hline Lingkungan pembelajaran & $127,45 \pm 16,22$ & Lebih banyak positif dibanding negatif \\
Proses pembelajaran & $30,63 \pm 4,31$ & Proses berlangsung baik dan dapat ditingkatkan \\
Pengajar & $27,93 \pm 4,46$ & Pengajar melaksanakan tugasnya dengan baik \\
Prestasi akademik & $22,94 \pm 3,12$ & Mahasiswa merasa prestasi akademiknya baik \\
Suasana pembelajaran & $28,70 \pm 5,21$ & Suasana pembelajaran yang positif mendorong \\
& & pembelajaran \\
Kehidupan sosial & $17,24 \pm 2,98$ & Lingkungan kampus yang positif mendorong \\
& & pembelajaran \\
\hline
\end{tabular}

Tabel 3. Perbandingan persepsi mahasiswa terhadap lingkungan pembelajaran berdasarkan jenis kelamin

\begin{tabular}{lccc}
\hline & Laki-laki & Perempuan & P Mann- \\
\cline { 2 - 3 } & \multicolumn{2}{c}{ Median (min-maks) } & Whitney \\
\hline Lingkungan pembelajaran (Maks 200) & $127,00(77-189)$ & $128,00(62-177)$ & 0,184 \\
Proses pembelajaran (Maks 48) & $30,00(16-43)$ & $32,00(11-43)$ & 0,114 \\
Pengajar (Maks 44) & $28,00(15-43)$ & $28,00(5-40)$ & 0,148 \\
Prestasi akademik (Maks 32) & $23,00(8-31)$ & $23,00(13-32)$ & 0,649 \\
Suasana pembelajaran (Maks 48 ) & $29,00(13-46)$ & $28,00(4-56)$ & 0,465 \\
Kehidupan Sosial (Maks 28) & $17,00(8-26)$ & $18,00(8-22)$ & 0,992 \\
\hline
\end{tabular}




\section{BAHASAN}

Kuesioner DREEM yang digunakan pada penelitian ini telah diterjemahkan ke dalam bahasa Indonesia dan memiliki validitas dan reliabilitas yang baik. Pada penelitian sebelumnya terbukti DREEM memiliki reliabilitas yang sangat tinggi (Crönbach's alpha > 0,7), ${ }^{8,9}$ dan untuk penelitian ini didapatkan koefisien reliabilitas alfa 0,804 yang juga termasuk dalam kategori reliabilitas sangat tinggi.

Pengukuran dengan menggunakan kuesioner DREEM yang diisi oleh 311 responden menunjukkan rerata skor DREEM ialah 127,45 (SB 16,22) dari skor maksimal 200. Hasil ini menunjukkan persepsi lingkungan pembelajaran 'lebih positif daripada negatif'. Menurut McAleer dan Roff rerata skor DREEM (101-150) mengindikasikan lingkungan pembelajaran yang positif namun masih terdapat beberapa hal yang peru diperbaiki. ${ }^{6}$

Hasil ini hampir sama dengan penelitian sebelumnya yang dilakukan di FK Unsrat ${ }^{10}$ pada tahun 2010 (123) dan Universitas Indonesia ${ }^{9}$ pada tahun 2008 $(120,10)$. Hasil rerata skor DREEM pada penelitian ini masih lebih tinggi dibandingkan hasil yang dilaporkan di Universitas Suez Canal Mesir $(113,8),{ }^{1}$ India $(107,44),{ }^{5}$ Universitas King Abdul Aziz Saudi Arabia (102), ${ }^{11}$ dan Universitas San'a (100). ${ }^{11}$ Sebaliknya, hasil ini masih lebih rendah daripada di Australia, ${ }^{12}$ Ingris, dan Universitas Tanjung Pura Indonesia. ${ }^{12-}$ 14

Banyak faktor yang dapat menjelaskan perbedaan nilai skor DREEM ini. Pertama, strategi pembelajaran problem based learning (PBL) terbukti lebih meningkatkan nilai lingkungan pembelajaran dibandingkan strategi pembelajaran konvensional. ${ }^{1} \quad$ Hal ini karena pada pada strategi pembelajaran PBL terdapat pendekatan yang mendorong mahasiswa untuk lebih bermotivasi dan bertanggung jawab terhadap lingkungan pembelajarannya sendiri. ${ }^{1,13}$ Brown dalam penelitiannya mendapatkan hasil DREEM yang sangat baik yaitu rerata skor DREEM 137,3. Hasil ini menurut Brown karena diterapkannya inovasi pembelajaran dengan pendekatan student-centered. ${ }^{12}$ Strategi pembelajaran dengan KBK dilaksanakan di FK Unsrat sejak tahun 2007. Dalam metode pembelajaran terdapat kelas kecil yaitu kelas tutorial untuk mendorong pendekatan student-centered. Dalam kelas tutorial mahasiswa diberikan masalah sesuai sasaran pembelajaran dan didorong untuk berdiskusi menyelesaikan masalah yang diberikan. Selain tutorial, metode pembelajaran lain yang dilakukan ialah kuliah pakar. Pendekatan student-centered pada kuliah pakar belum efektif dilakukan. Metode pembelajaran tutorial dapat menjadi salah satu alasan bagi mahasiswa untuk memberikan hasil skor DREEM lebih banyak positif dibandingkan negatif tapi belum mendapatkan angka yang maksimal karena kuliah pakar belum medorong pendekatan student centered.

Faktor kedua yaitu perbedaan program penerimaan dalam pendidikan kedokteran. Program penerimaan mahasiswa kedokteran di FK Unsrat mengikuti program penerimaan nasional, terdiri dari jalur Seleksi Nasional Masuk Perguruan Tinggi Negeri (SNMPTN), Seleksi Bersama Masuk Perguruan Tinggi Negeri (SBMPTN), dan jalur mandiri. Perbedaan program penerimaan menurut Youssef et al. ${ }^{1}$ dapat memberikan perbedaan dalam kriteria penerimaan mahasiswa dan ekspektasi yang berbeda dari mahasiswa terhadap lingkungan pembelajaran.

Faktor-faktor lain yang dapat meningkatkan nilai DREEM dapat dilihat melalui berbagai penelitian lain yang memiliki nilai DREEM tinggi. Hasil penelitian Varma et al. ${ }^{14}$ di delapan rumah sakit pendidikan Ingris mendapatkan rerata skor DREEM 139. Menurut Varma hasil yang lebih positif ini karena adanya pembelajaran yang komprehensif dan penilaian diri secara formatif selama proses pembelajaran dengan mengikuti panduan melalui buku pegangan maupun panduan yang berbasis elektronik. Hasil skor DREEM yang tinggi lainnya didapatkan di Universitas Tanjung Pura Indonesia yaitu 142,55. Menurut Arundina et al. ${ }^{13}$ beberapa 
hal yang mendukung lingkungan pembelajaran di Universitas Tanjung Pura, antara lain: penggunaan strategi pembelajaran PBL, dosen yang berpengalaman sebagai fasilitator, dan sarana prasarana yang mendukung seperti tersedianya laboratorium uji kompetensi berbasis komputer dan berbasis ketrampilan (OSCE).

Nilai rerata pada tiap subskala belum memberikan hasil yang maksimal, namun menunjukkan hasil yang cukup baik. Pada subskala proses pemebelajaran, nilai rerata 30,63 menunjukkan persepsi yang lebih positif. Pada subskala pengajar, nilai reratanya 27,93, yang berarti staf pengajar telah melaksanakan tugasnya dengan baik. Subskala prestasi akademis memberikan nilai rerata 22,94 yang berarti mahasiswa merasa prestasi akademiknya positif. Subskala suasana pembelajaran dengan rerata 28,70 menunjukkan suasana pembelajaran yang kondusif untuk meningkatkan proses pembelajaran. Subskala kehidupan sosial dengan rerata 17,24 menunjukkan lingkungan institusi yang mendukung proses pembelajaran. Seluruh hasil ini berada pada rentang nilai satu tingkat di bawah rentang nilai yang sangat baik. Untuk meningkatkan lingkungan pembelajaran di FK Unsrat, evaluasi kurikulum melalui evaluasi lingkungan pembelajaran juga perlu dilakukan secara berkala. Hal ini bertujuan untuk terus memperbaiki kekurangan dalam kurikulum sehingga menghasilkan lingkungan pembelajaran yang optimal untuk meraih prestasi akademik yang maksimal. ${ }^{1}$

Hasil penelitian menunjukkan mahasiswa laki-laki dan perempuan di FK UNSRAT mempersepsikan lingkungan pembelajaran dengan hasil 'lingkungan pembelajaran yang lebih banyak positif daripada negatif' (101-150) dengan median laki-laki sedikit lebih rendah daripada perempuan (total median skor DREEM perempuan 128 sedangkan laki-laki 127). Persepsi mahasiswa kedokteran perempuan terhadap lingkungan pembelajaran lebih baik daripada mahasiswa laki-laki didapatkan pada penelitian di Australia ${ }^{12}$ dan Pakistan. ${ }^{15}$ Sebaliknya, Abraham melaporkan bahwa persepsi mahasiswa laki-laki terhadap lingkungan pembelajaran lebih baik dibandingkan mahasiswa perempuan di India. ${ }^{16}$

Hasil penelitian ini juga menunjukkan tidak adanya hubungan bermakna antara jenis kelamin dengan persepsi lingkungan pembelajaran dan subskala persepsi terhadap pengajar, prestasi akademik, suasana pembelajaran, dan kehidupan sosial $(P<0,05)$. Hal ini mungkin dikarenakan mahasiswa laki-laki dan perempuan memiliki kemampuan yang sama dalam mengikuti proses pembelajaran. ${ }^{1}$

\section{SIMPULAN}

Lingkungan pembelajaran di FK Unsrat yang telah menerapkan PBL sejak tahun 2007, dinilai mahasiswa dengan nilai rerata DREEM 127,45 atau lingkungan pembelajaran yang lebih banyak positif daripada negatif.

\section{SARAN}

Faktor penting yang perlu dipertimbangkan untuk meningkatkan lingkungan pembelajaran yaitu pembelajaran dengan pendekatan student-centered, manajemen asesmen/penilaian formatif, kesuksesan strategi pembelajaran PBL dengan tersedianya dosen berpengalaman dan sarana prasarana yang mendukung. Selain itu evaluasi lingkungan pembelajaran secara berkala penting untuk dilakukan untuk mengevaluasi kelebihan dan kekurangan dari kurikulum dan memperbaikinya.

\section{DAFTAR PUSTAKA}

1. Youssef WT, Mohamed Y, Wazir E, Ghaly MS, Aly R, Khadragy E. Evaluation of the learning environment at the Faculty of Medicine, Suez Canal University: Students' perceptions. Intellect Prop Rights Open Access. 2013;1(1):1-7.

2. Genn JM. AMEE Medical Education Guide No. 23 (Part 1): Curriculum, environment, climate, quality and 
change in medical education - a unifying perspective. Med Teach. 2001;23(5): 445-54.

3. World Federation for Medical Education. Basic Medical Education WFME Global Standards for quality improvement. Copenhagen: WFME, 2007; p. 9-16.

4. Wayne SJ, Fortner SA, Kitzes JA, Timm C, Kalishman S. Cause or effect? The relationship between student perception of the medical school learning environment and academic performance on USMLE Step 1. Med Teach. 2013;35(5):376-80.

5. Mayya SS, Roff SUE. Students' perceptions of educational environment: a comparison of academic achievers and under-achievers at Kasturba Medical College, India. Educ Heal. 2004;17(3): 280-291.

6. McAleer S, Roff S. Learning environment. In: Dent JA, Harden RM, editors. A Practical Guide for Medical Education (4th ed). Churcil Livingstone Elsevier, 2013; p. 392-9.

7. Miles S, Swift L, Leinster SJ. The Dundee Ready Education Environment Measure (DREEM): a review of its adoption and use. Med Teach. 2012;34(9):620-634.

8. Leman MA. Construct validity assessment of Dundee Ready Educational Environment Measure (DREEM) in a school of dentistry. Pendidik Kedokt Indones. 2017;6(43):11-9.

9. Soemantri D, Roff S, McAleer S. Student perceptions' of the educational environment in the midst of curriculum change. Med J Indones. 2008;17(1):5763.

10. Wowor PM, Mewo YM, Dehoop JJ, Manoppo FP, Memah MF. Persepsi mahasiswa terhadap atmosfir pendidikan di Fakultas Kedokteran Universitas Sam Ratulangi. J Perpipki. 2011;2:1-8.

11. Al-hazimi A, Zaini R, Karunathilake I, Roff SUE, Aleer SMC, Davis $M$. Educational environment in traditional and innovative medical schools: a study in four undergraduate Medical Schools. 2004;17(2):192-203.

12. Brown T, Williams B, Lynch $M$. The Australian DREEM: evaluating student perceptions of academic learning environments within eight health science courses. Int J Med Educ. 2011;2:94-101.

13. Arundina A, Tejoyuwono T, Armyanti I, Nugraha RP. Gambaran evaluasi penilaian mahasiswa program. $\mathbf{J}$ Pendidik Kedokt Indones. 2015;4(3): 109-114.

14. Varma R, Tiyagi E, Gupta JK. Determining the quality of educational climate across multiple undergraduate teaching sites using the DREEM inventory. BMC Med Educ. 2005;5(1):8.

15. Rehman R, Ghias K, Fatima SS, Hussain M, Alam F. Dream of a conducive learning environment: one DREEM for all medical students! J Pak Med Assoc. 2017;67(1):7-11.

16. Abraham R, Ramnarayan $K$, Vinod $P$, Torke S. BMC Medical Education. 2008;5(Mmmc):1-5. doi:10.1186/14726920-8-20. 